\title{
Áreas Protegidas do Pampa - Argentina, Brasil e Uruguai: análise da distribuição espacial e correlação das diferentes categorias
}

\author{
Protected Areas of Pampa- Argentina, Brazil e Uruguay: spatial distribution analysis \\ and correlation of different categories
}

\section{Zonas Protegidas en el Pampa - Argentina, Brasil y Uruguay: análisis de distribución espacial y correlación de diferentes categorías}

\author{
Alice Poche Gabriel ${ }^{1}$
}

https://orcid.org/ 0000-0002-5006-5895

Franciele da Silva ${ }^{2}$

https://orcid.org 0000-0003-2853-7187

Eliane Maria Foleto ${ }^{3}$

https://orcid.org/ 0000-0003-2205-7801

\begin{abstract}
RESUMO: As Áreas Protegidas figuram como territórios demarcados cuja principal função é a conservação e/ou preservação da biodiversidade e/ou aspectos culturais importantes a elas associadas. Desse modo, esta pesquisa tem por objetivo identificar e espacializar as Áreas Protegidas do Pampa - Argentina, Brasil e Uruguai, discutindo as terminologias adotadas por cada país e quantificando a extensão territorial de proteção dessas áreas para o Pampa. Para tanto, utilizou-se do método quantitativo e análise dos dados em ambiente SIG (Sistema de Informação Geográfica). Através da identificação e espacialização das áreas pode-se concluir que existem 122 Áreas Protegidas no Pampa, sendo 69 na Argentina, 40 no Brasil e 13 no Uruguai, perfazendo um total de 1.175.014,9 hectares. O predomínio dessas áreas é da categoria de proteção integral (64 ao total), estando 46 delas na Argentina. No Brasil e Uruguai a categoria que predomina é a de uso sustentável, sendo, respectivamente, 26 e 9 Áreas Protegidas. Conclui-se que a representatividade das Áreas Protegidas no Pampa é baixa, sobretudo analisando quantidade e tamanho das áreas já instituídas, que cobrem $1,5 \%$ da área total do Pampa, necessitando, desse modo, mais ações para a proteção do bioma, considerando as ameaças que o Pampa sofre, principalmente, em relação à inserção de monoculturas como a soja e a silvicultura.
\end{abstract}

\footnotetext{
${ }^{1}$ Mestranda no Programa de Pós-Graduação em Geografia da UFSM, na linha de pesquisa Dinâmicas da Natureza e Qualidade Ambiental do Cone Sul. E-mail: alicepoche@gmail.com.

2 Doutora em Geografia pela Universidade Federal de Santa Maria (2019), na linha de pesquisa Dinâmicas da Natureza e Qualidade Ambiental do Cone Sul. Professora no Instituto Federal Farroupilha - campus São Vicente do Sul. E-mail: francieli17@gmail.com.

${ }^{3}$ Doutora em Engenharia de Produção pela Universidade Federal de Santa Catarina (2003). Professora Associada da Universidade Federal de Santa Maria. E-mail: efoleto@gmail.com.
} 
Áreas Protegidas do Pampa - Argentina, Brasil e Uruguai: análise da distribuição espacial e...

PALAVRAS-CHAVE: Pampa. Áreas Protegidas. Categorias. IUCN.

\begin{abstract}
Protected Areas appear as demarcated territories whose main function is the conservation and/or preservation of biodiversity and/or important cultural aspects associated with them. Thus, this research aims to identify the Protected Areas and analyze their spatial distribution in Pampa - Argentina, Brazil e Uruguay, discussing the terminologies adopted by each country and quantifying the territorial extent of protection of these areas for the Pampa. For this, we used the quantitative method and data analysis in GIS (Geographic Information System). Through the identification and spatialization of the areas it can be concluded that there are 122 Protected Areas in Pampa, 69 in Argentina, 40 in Brazil and 13 in Uruguay, making a total of 1,175,014.9 hectares. These areas predominate in the full protection category (64 in total), being 46 of them in Argentina. In Brazil and Uruguay, the predominant category is sustainable use, with 26 and 9 Protected Areas, respectively. It is concluded that the representativeness of the Protected Areas in the Pampa is low, especially analyzing the quantity and size of the areas already established, which cover $1.5 \%$ of the total area of the Pampa, thus requiring more actions for the protection of the biome, the threats that Pampa suffers, mainly, in relation to the insertion of monocultures such as soy and forestry.
\end{abstract}

KEYWORDS: Pampa. Protected Areas. Categories. IUCN.

RESUMEN: Las Áreas Protegidas aparecen como territorios demarcados cuya función principal es la conservación y/o preservación de la biodiversidad y/o aspectos culturales importantes asociados con ellas. Por lo tanto, esta investigación tiene como objetivo identificar Áreas Protegidas y analizar su distribución espacial en Pampa - Argentina, Brasil y Uruguay, discutir la terminología adoptada por cada país y cuantificar el alcance territorial de protección de estas áreas para la Pampa. Para esto, utilizamos el método cuantitativo y el análisis de datos en un entorno SIG (Sistema de Información Geográfica). A través de la identificación y espacialización de las áreas se puede concluir que hay 122 Áreas Protegidas en la Pampa, 69 en Argentina, 40 en Brasil y 13 en Uruguay. Estas áreas predominan en la categoría de protección completa (64 en total), con 46 de ellas en Argentina. En Brasil y Uruguay, la categoría predominante es el uso sostenible, con 26 y 9 Áreas Protegidas, respectivamente. Se concluye que la representatividad de las Áreas Protegidas en la Pampa es baja, especialmente analizando la cantidad y tamaño de las áreas ya establecidas, las cuales cubren el $1.5 \%$ del área total de la Pampa, requiriendo así más acciones para la protección de el bioma, considerando las amenazas que sufre Pampa, principalmente, en relación con la inserción de monocultivos como la soja y la silvicultura.

PALABRAS CLAVES: Pampa. Áreas Protegidas. Categorías. IUCN.

\title{
INTRODUÇÃO
}

As paisagens do Pampa, distribuídas ao longo do Cone Sul, compartilhadas entre Brasil, Argentina e Uruguai (figura 1), guardam a marca de uma natureza que se fez paisagem através da ação humana, sobretudo com a inserção do gado pelos jesuítas, em meados de 1630 (POSSAMAI, 2006). Enraizado pela cultura ligada a essa herança histórica, o Pampa guardará por muito tempo uma relação entre atividade pecuária de forma extensiva e seu território de campos.

Predominantemente composto por relevos planos - característica que, inclusive, dá origem ao nome Pampa, que na língua indígena quéchua significa área plana - sob 
extensas áreas de campos ou pastizales, como denominam os vizinhos de origem espanhola Argentina e Uruguai, guardam um ecossistema com alta diversidade de espécies vegetais e animais (SUERTEGARAY; SILVA, 2009). Além disso, os campos pampeanos, como apontam Tornquist e Bayer (2009), garantem serviços ambientais importantes, como a conservação de recursos hídricos, a disponibilidade de polinizadores, o provimento de recursos genéticos, e a retenção de gás carbônico; e, têm sido a principal fonte forrageira para a pecuária, além de oferecer beleza cênica com potencial turístico importante.

Figura 1 - Mapa de localização do Pampa Argentina, Brasil e Uruguai

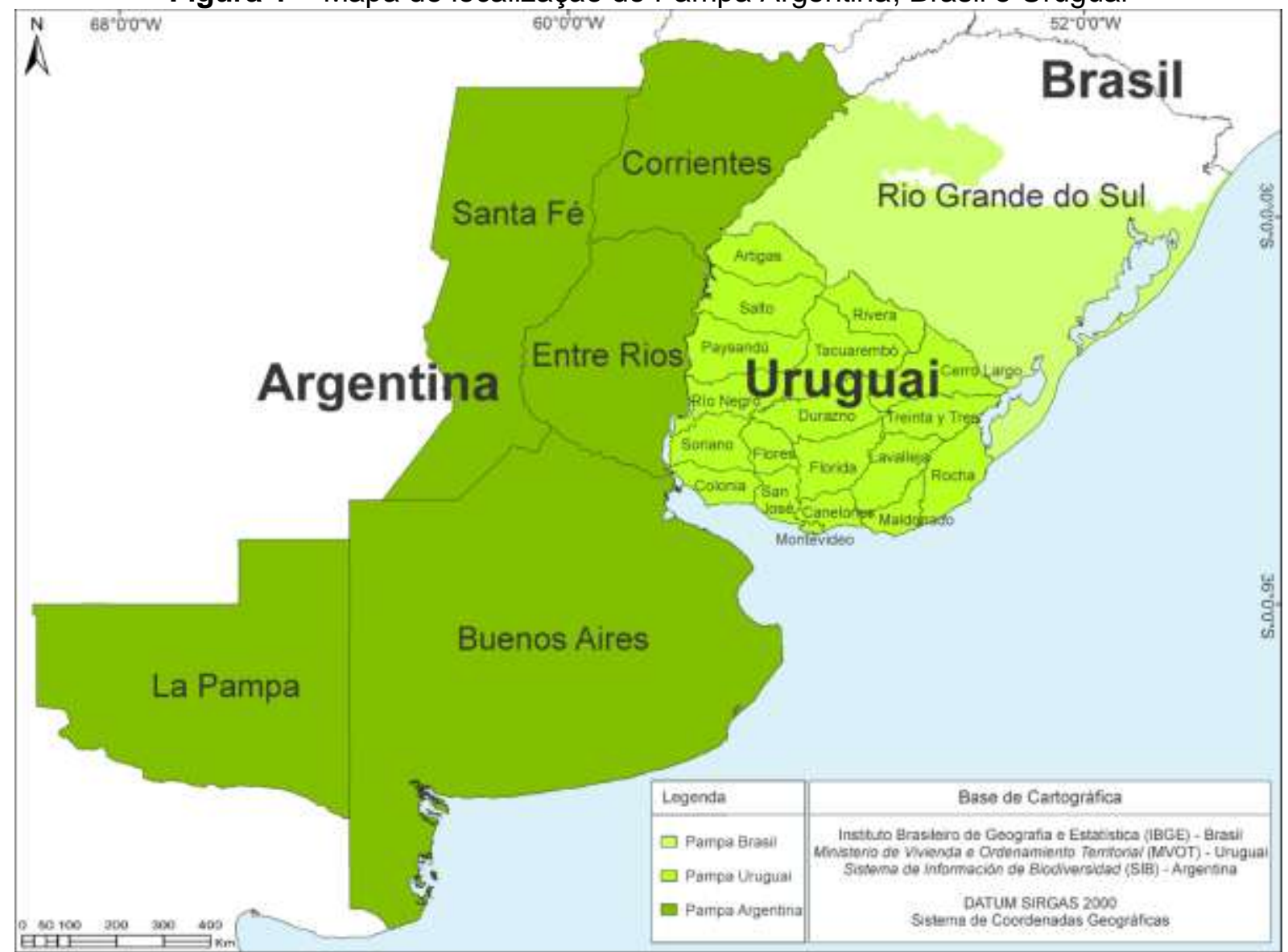

Fonte: adaptado de Suertegaray e Silva (2009).

Embora aos olhos do leigo possa parecer simples, e talvez homogêneo, o Pampa reúne diferentes formações ecológicas, como cita Bencke (2016), compostas além dos campos, por matas ciliares e matas de encostas, áreas úmidas, campos com espinilhos (Vachellia caven) e campos litorâneos. Todavia, essa diversidade está ameaçada, sobretudo, por uma economia regional baseada em commodities, que transformam o Pampa, convertendo a sua matriz original.

Áreas em processo avançado de arenização, êxodo rural, lavouras extensas para a exploração silvícola, forte inserção da soja transgênica com seus agrotóxicos, mineração, 
entre outros tantos, simbolizam os conflitos dos usos dos recursos naturais do Pampa que são citados em (FIGUEIRÓ; SELL, 2020).

Para Chomenko (2016), o Pampa, caracterizado pela presença do cavalo, do gado, o campo aberto e a figura do gaúcho, simbolizam aspectos culturais que compõem a paisagem, e essas características alteram-se, de forma mais intensa, em virtude do avanço, principalmente, das monoculturas de soja e da silvicultura em larga escala. Em razão disso, é essencial entender, no momento em que se discutem as transformações no Pampa, que não se está expondo apenas os aspectos econômicos e ambientais, mas do mesmo modo as mudanças sociais e culturais que estão ocorrendo neste território.

Perante essa realidade, começa-se a perceber a necessidade de intervenções e a busca de alternativas para reduzir e impossibilitar o avanço deste cenário crítico de conversão e esgotamento do patrimônio natural e cultural do Pampa. Não serão apenas os campos que se converterão em extensas áreas de cultivos de soja ou silvicultura, existe toda uma biodiversidade e uma cultura ameaçada. Desse modo, é importante ressaltar que além de necessitar urgentemente de políticas de conservação, a região do Pampa demanda estratégias que considerem também a presença humana, sobretudo, pela principal característica cultural da área: a criação do gado de forma extensiva.

Nesse contexto citam-se as Áreas Protegidas que, segundo Scherl et al. (2006, p. 7-8) caracterizam-se por ser "[...] uma área de terra e/ou mar especialmente dedicada à proteção e manutenção da biodiversidade, os recursos naturais e culturais associados e geridos através de meios legais ou outros eficazes". Essas áreas possuem como característica tanto o caráter preservacionista como conservacionista, representadas no papel das Áreas Protegidas de Proteção Integral e as de Uso Sustentável, respectivamente.

Em suma, como esclarece Diegues (2002), o conceito de preservação está relacionado aos métodos e políticas que visam a proteção em longo prazo dos ecossistemas, tornando-os ilhas intocadas, nas palavras do autor, onde o ser humano praticamente não interage com o ambiente. Já a conservação está relacionada ao manejo do uso humano dos ecossistemas, apoiado, principalmente, em bases sustentáveis, garantindo a relação sociedade e natureza da forma mais harmônica possível.

Desse modo, considerando a realidade e abrangência do Pampa nos três países Argentina, Brasil e Uruguai, propõe-se, como objetivo da pesquisa, quantificar as Áreas Protegidas instituídas, analisara distribuição espacial e extensão territorial das mesmas, bem como discutir as terminologias das áreas adotadas por cada um dos países. 


\section{COMPREENDENDO AS ÁREAS PROTEGIDAS DA ARGENTINA, BRASIL E URUGUAI}

Tendo em vista que a distribuição espacial do Pampa ultrapassa as fronteiras nacionais, é importante, primeiramente, compreender como as Áreas Protegidas são abordadas em cada país, considerando que, conforme se ultrapassam os limites, os conceitos e normas que as regem também são modificados. 2000

No Brasil, as Áreas Protegidas estão sistematizadas, dentre outras, através do Sistema Nacional de Unidades de Conservação (SNUC) - Lei n 9.985/ (BRASIL, 2000), divididas em 12 categorias, sendo cinco de proteção integral e sete de uso sustentável. Em relação ao Rio Grande do Sul tem-se o Sistema Estadual de Unidades de Conservação (SEUC), com características muito semelhantes ao âmbito federal, estabelecido através do Decreto Estadual n 53.037/2016 (RIO GRANDE DO SUL, 2016), conforme pode ser observado no Quadro 1.

Também se configuram como Áreas Protegidas, no país, as Áreas de Preservação Permanente (APP) e Reservas Legais - estabelecidas através da Lei 12.651/2012 (BRASIL, 2012), as quais possuem a função de conectividade entre os fragmentos de áreas conservadas; bem como as terras indígenas e quilombolas, reconhecidas como Áreas Protegidas pelo Decreto $n^{\circ}$ 5.758/2006 (BRASIL, 2006), tendo em vista o caráter sustentável de uso de seus territórios.

Já o Uruguai, tem suas Áreas Protegidas sistematizadas através do Sistema Nacional de Áreas Protegidas (SNAP), por meio da Lei $n^{\circ}$ 17.234/2000 (URUGUAI, 2000), e a Argentina, assim como o Brasil, possui um sistema em esfera nacional - Sistema Nacional de Áreas Protegidas (SNAP), regido pela Lei n²2.351/1980 (ARGENTINA, 1980) - além dos Sistemas Provinciais de Áreas Protegidas (SPAP) estabelecidos pela legislação de cada província, como pode ser observado no quadro 2. Os dois países sistematizam suas Áreas Protegidas semelhantemente às Unidades de Conservação brasileiras, porém utilizando-se das categorias propostas pela IUCN (International Union for ConservationofNature) para diferenciá-las, além de ambos adotarem a proteção integral e o uso sustentável como modalidades de manejo para classificá-las (quadro 3). No quadro 2 pode ser observado a sistematização e classificação utilizada por Argentina e Uruguai para suas Áreas Protegidas situadas no Pampa.

A IUCN é uma organização financiada por governos, agências bilaterais e multilaterais, fundações e corporações, que detem status de observadora na ONU Organização das Nações Unidas, FAO - Food and Agriculture Organization of the United Nations, e UNESCO - United Nations Educational, Scientific and Cultural Organization. E é através dela que desde 1948 buscam-se alternativas de preservação e conservação de ecossistemas, em âmbito global (BISHOP et al., 2004). 
Áreas Protegidas do Pampa - Argentina, Brasil e Uruguai: análise da distribuição espacial e...

Quadro 1 - Sistematização das Áreas Protegidas brasileiras, com enfoque para as Unidades de Conservação

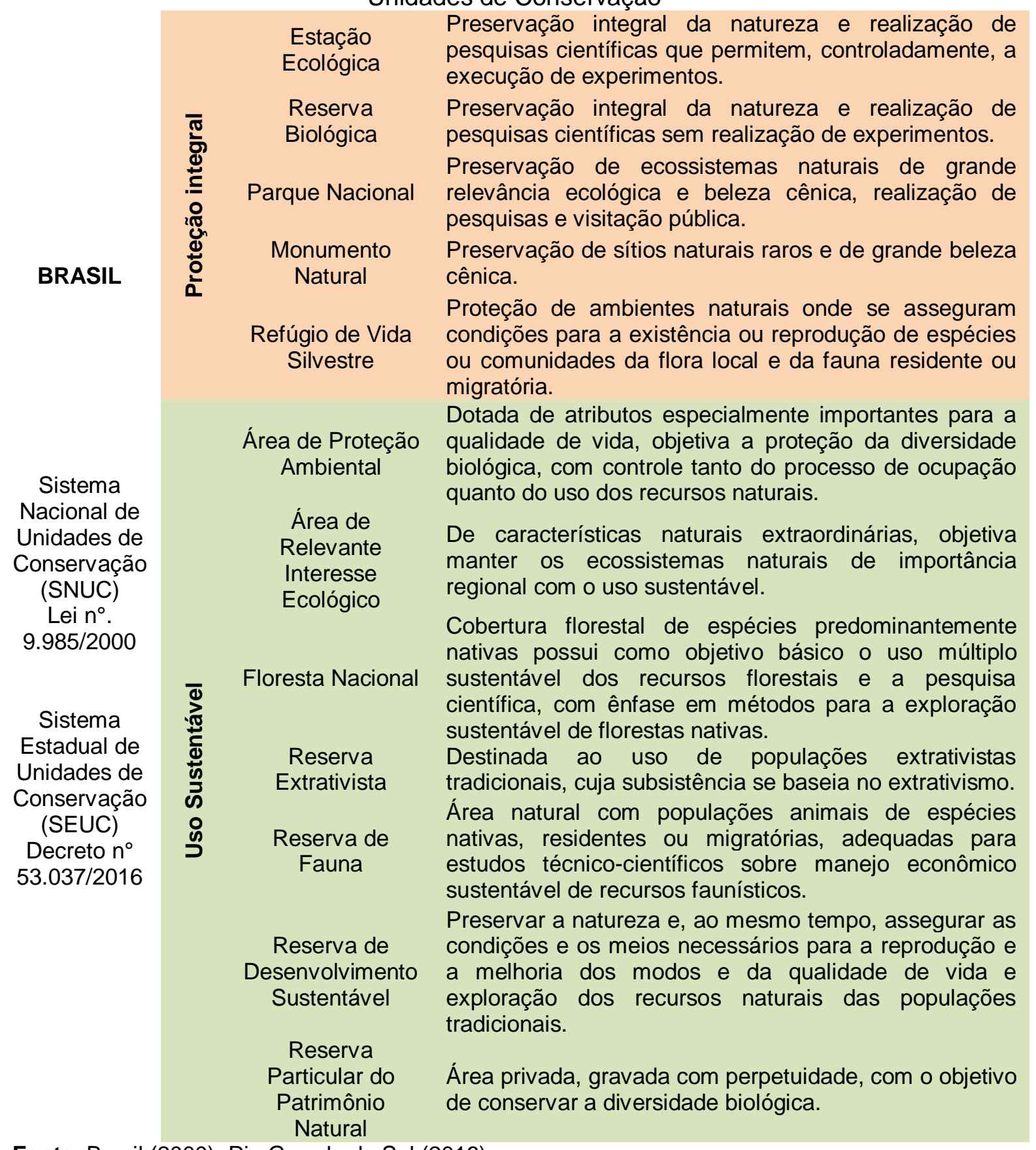

Fonte: Brasil (2000); Rio Grande do Sul (2016).

Ainda segundo os autores, desde sua criação, objetiva-se discutir e desenvolver um sistema de Áreas Protegidas, organizando e definido tipologias, que abarcam tanto a proteção de forma integral, quanto à utilização de forma sustentável, a fim de criar um entendimento comum e uma estrutura de referência internacional para Áreas Protegidas entre os países. 


\begin{tabular}{|c|c|c|c|}
\hline País/lei & & $\begin{array}{l}\text { Istemat } \\
\text { Catego }\end{array}$ & $\begin{array}{c}\text { as Areas Protegidas de Argentina } \\
\text { Objetivos }\end{array}$ \\
\hline & & Reserva Natural & Proteção integral do ecossistema, sem acesso ao público \\
\hline ARGENTINA & & Estrita & e limitadas atividades de pesquisa. \\
\hline $\begin{array}{c}\text { Sistema } \\
\text { Nacional de }\end{array}$ & 产 & $\begin{array}{l}\text { Área Natural } \\
\text { Silvestre }\end{array}$ & $\begin{array}{l}\text { Proteção da diversidade biológica em paisagens e } \\
\text { ambientes que estão livres de perturbação humana } \\
\text { durante um período prolongado de tempo. }\end{array}$ \\
\hline $\begin{array}{l}\text { Áreas } \\
\text { Protegidas } \\
\text { (SNAP) }\end{array}$ & 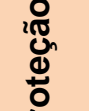 & $\begin{array}{l}\text { Parque } \\
\text { Nacional ou }\end{array}$ & $\begin{array}{l}\text { Proteção integral do ecossistema, com acesso ao público } \\
\text { e limitadas atividades de pesquisa. }\end{array}$ \\
\hline $\begin{array}{l}\text { Leyn } \\
22.351 / 1980\end{array}$ & 0 & & $\begin{array}{l}\text { Proteção integral de áreas raras com importância } \\
\text { natural/cultural de valor único. }\end{array}$ \\
\hline $\begin{array}{l}\text { Ley } \\
\text { Provincial de }\end{array}$ & & $\begin{array}{l}\text { Reserva } \\
\text { Nacional }\end{array}$ & $\begin{array}{l}\text { Utilização sustentável dos ecossistemas naturais } \\
\text { importantes. }\end{array}$ \\
\hline $\begin{array}{l}\text { Buenos Aires } \\
n^{\circ} \\
10.907 / 1990 .\end{array}$ & $\sum_{\text {త]త }}^{\bar{\Phi}}$ & $\begin{array}{l}\text { Reserva Natural } \\
\text { Privada de Uso } \\
\text { Múltiplo }\end{array}$ & $\begin{array}{l}\text { Área privada cujo patrimônio territorial pertence a uma ou } \\
\text { mais pessoas, destinadas ao uso sustentável. }\end{array}$ \\
\hline $\begin{array}{l}\text { Ley } \\
\text { Provincial de } \\
\text { Entre Ríos } n^{\circ}\end{array}$ & 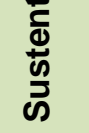 & $\begin{array}{l}\text { Reserva Natural } \\
\text { com Recursos } \\
\text { Manejados }\end{array}$ & $\begin{array}{l}\text { Área de domínio público, de importância biológica, } \\
\text { destinada ao uso sustentável. }\end{array}$ \\
\hline 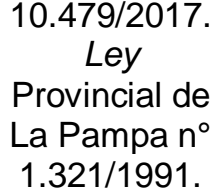 & \& & $\begin{array}{l}\text { Paisagem } \\
\text { Protegida }\end{array}$ & $\begin{array}{l}\text { Paisagens naturais, seminaturais e/ou de importância } \\
\text { cultural, dignos de ser conservados em sua condição } \\
\text { tradicional, com interação humana e adequado manejo da } \\
\text { terra. }\end{array}$ \\
\hline URUGUAI & 赵, & $\begin{array}{l}\text { Parque } \\
\text { Nacional }\end{array}$ & $\begin{array}{l}\text { Proteção integral do ecossistema, com acesso ao público } \\
\text { e limitadas atividades de pesquisa. }\end{array}$ \\
\hline & & $\begin{array}{l}\text { Monumento } \\
\text { Natural }\end{array}$ & $\begin{array}{l}\text { Proteção integral de raros elementos naturais, com } \\
\text { notável importância nacional. }\end{array}$ \\
\hline $\begin{array}{l}\text { Nacional de } \\
\text { Áreas } \\
\text { Protegidas }\end{array}$ & 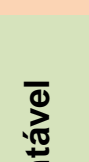 & $\begin{array}{l}\text { Áreas de } \\
\text { Manejo de } \\
\text { Habitat e/ou } \\
\text { Fsnécies }\end{array}$ & $\begin{array}{l}\text { Áreas passíveis de manejo onde se deve garantir a } \\
\text { manutenção dos habitat e/ou satisfazer as necessidades } \\
\text { de determinadas espécies. }\end{array}$ \\
\hline $17.234 / 2000$ & $\stackrel{\Phi}{د}$ & $\begin{array}{l}\text { Paisagem } \\
\text { Protegida }\end{array}$ & $\begin{array}{l}\text { Área com interação entre ser humano e natureza, de } \\
\text { singular beleza, com valor natural, ecológico e cultural. }\end{array}$ \\
\hline & \& & $\begin{array}{l}\text { Área Protegida } \\
\text { com Recursos } \\
\text { Manejados }\end{array}$ & $\begin{array}{l}\text { Áreas que apresentam sistemas naturais } \\
\text { predominantemente não modificados, onde através do } \\
\text { manejo de atividades se pretende garantir a proteção e a } \\
\text { manutenção da diversidade biológica. }\end{array}$ \\
\hline
\end{tabular}

Fonte: Argentina (1980, 1991, 2017), Buenos Aires (1990), Uruguai (2000).

Todavia, o Brasil, em sua vasta extensão territorial e com a diversidade e peculiaridades de seus biomas, adotou um sistema com tipologias próprias para as unidades de conservação. Esse sistema começa a ser moldado em 1937, através da instituição do primeiro Parque Nacional do país: o Parque Nacional de Itatiaia, evento que marca o início concreto da poítica de estabelecimento e gerenciamento de Áreas Protegidas no Brasil (MEDEIROS; GARAY, 2006), instituído por meio do Código Florestal de 1934 (MEDEIROS; IRVING; GARAY, 2004).

Desde então, o que se observa no modelo de proteção adotado no país é a capacidade de ter estabelecido distintas tipologias de Áreas Protegidas voltadas para uma 
gestão ambiental do território, tipologias essas que são apresentadas e discutidas ao longo do trabalho.

\begin{tabular}{|c|c|c|}
\hline & Categorias & Objetivos de Conservação \\
\hline \multirow{4}{*}{ 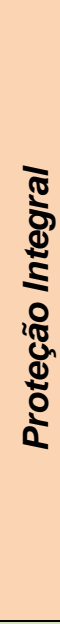 } & $\begin{array}{l}\text { Reserva Natural } \\
\text { Estrita }\end{array}$ & $\begin{array}{l}\text { Conservar ecossistemas regionais, nacionais ou globais, espécies } \\
\text { e/ou características extraordinárias da geodiversidade: estes } \\
\text { atributos foram formados principalmente ou exclusivamente por } \\
\text { forças não humanas e seriam degradados ou destruídos se fossem } \\
\text { submetidos a qualquer impacto humano significativo. }\end{array}$ \\
\hline & $\begin{array}{l}\text { Área Natural } \\
\text { Silvestre }\end{array}$ & $\begin{array}{l}\text { Proteger a integridade ecológica de longo prazo das áreas naturais, } \\
\text { sem atividades humanas significativas, livre de infraestrutura } \\
\text { moderna e dominado por forças e processos naturais, para que as } \\
\text { gerações atuais e futuras tenham a oportunidade de vivenciar } \\
\text { essas áreas. }\end{array}$ \\
\hline & Parque Nacional & $\begin{array}{l}\text { Proteger a biodiversidade natural em conjunto com a estrutura } \\
\text { ecológica subjacente e os processos ambientais sobre os quais se } \\
\text { apoia, e promover a educação e o uso recreativo. }\end{array}$ \\
\hline & $\begin{array}{c}\text { Monumento } \\
\text { natural }\end{array}$ & $\begin{array}{l}\text { Proteger características naturais específicas, a biodiversidade e os } \\
\text { habitats associados a elas. }\end{array}$ \\
\hline \multirow{3}{*}{ 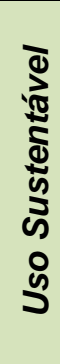 } & $\begin{array}{l}\text { Área de manejo de } \\
\text { habitat / espécies }\end{array}$ & Manter, conservar e restaurar espécies e habitats. \\
\hline & $\begin{array}{l}\text { Paisagem terrestre e } \\
\text { marinha protegida }\end{array}$ & $\begin{array}{l}\text { Proteger e manter importantes paisagens terrestres/marinhas e a } \\
\text { conservação da natureza associada a elas, bem como outros } \\
\text { valores criados por interações com os seres humanos através de } \\
\text { práticas tradicionais de manejo. }\end{array}$ \\
\hline & $\begin{array}{l}\text { Área protegida } \\
\text { manejada }\end{array}$ & $\begin{array}{l}\text { Proteger os ecossistemas naturais e usar os recursos naturais de } \\
\text { maneira sustentável, quando a conservação e o uso sustentável } \\
\text { puderem beneficiar-se mutuamente. }\end{array}$ \\
\hline
\end{tabular}

Fonte: adaptado e traduzido de Dudley (2008).

\section{MATERIAIS E MÉTODOS}

Para alcançar o objetivo proposto para o trabalho, foi utilizado o método quantitativo. Conforme cita Richardson (1999), o método quantitativo permite a escolha de procedimentos sistemáticos para a descrição e explicação dos fenômenos e, desse modo, é possível garantir os resultados, evitando distorções na interpretação.

Quanto aos procedimentos técnicos da pesquisa, em um primeiro momento foi elaborada a revisão e sistematização dos marcos institucionais ambientais de cada país, objetivando a identificação das diferentes categorias de Áreas Protegidas, compiladas no quadro 1.

Posteriormente, foi realizada a categorização das Áreas Protegidas encontradas no Pampa, de acordo com as categorias propostas pela IUCN, considerando que suas recomendações e parâmetros técnicos são aplicados em nível global, tornando possível, assim, relacionar as Áreas Protegidas encontradas nos diferentes territórios políticosadministrativos do Pampa. 
Após a sistematização e identificação foi organizado o banco de dados para a espacialização das diferentes categorias de Áreas Protegidas. Os atributos compilados foram: nome, categoria, localização e extensão das áreas. As informações foram retiradas para o território brasileiro do Ministério do Meio Ambiente (BRASIL, 2020) e Secretaria do Meio Ambiente e Infraestrutura do Rio Grande do Sul (PORTO ALEGRE, 2020), Ministerio de Vivienda Ordenamiento Territorial y Medio Ambiente do Uruguai (URUGUAI, 2020) e do Sistema de Información de Biodiversidad de la Administración de Parques Nacionales - SIB (ARGENTINA, 2020).

A síntese final dos resultados alcançados foi à elaboração de um mapa como a identificação das Áreas Protegidas encontradas no Pampa, bem como a relação entre a extensão territorial de áreas conservadas por categoria da IUCN, no Pampa.

\section{RESULTADOS E DISCUSSÃO}

Conforme delimitado nos objetivos da pesquisa, buscou-se identificar e espacializar as Áreas Protegidas localizadas no Pampa Argentina, Brasil e Uruguai. Desse modo, primeiramente, foi elaborada uma sistematização das categorias adotadas em cada país, agrupando-as conforme os objetivos de conservação e formas de manejo, seguindo como eixo norteador a categorização proposta pela IUCN. Essa sistematização pode ser observada no quadro 4.

Através do quadro 4 buscou-se um diálogo entre as categorias de Áreas Protegidas existentes no Pampa, comparando os objetivos de conservação e manejo, com as categorias propostas pela IUCN. Essa padronização é importante para que a compreensão das Áreas Protegidas ultrapasse as fronteiras dos países que compõem o Pampa, utilizando-se de uma fonte internacional para unificar a análise.

Ainda com a análise do quadro 4 é possível perceber que Argentina e Uruguai possuem categorias idênticas ou de nomenclatura muito similares às da IUCN, diferenciando-se o Brasil que possui 12 categorias em sua diretriz, das quais seis estão instituídas no Pampa brasileiro. Torna-se aqui importante reforçar que o agrupamento das Áreas Protegidas conforme a categorização da IUCN, no caso brasileiro, foi realizado somente com aquelas categorias que estão presentes no Pampa, não sendo considerada a totalidade das Áreas Protegidas instituídas pelo SNUC para esta sistematização.

Por meio da identificação e do agrupamento das categorias de Áreas Protegidas que se relacionam conforme seus objetivos de manejo e gestão foi possível elaborar o mapa síntese da pesquisa. Para a elaboração do mapa foi realizada a correlação entre as categorias de cada área identificada com as categorias da IUCN, unificando, deste modo, a análise. 
Quadro 4 - Correspondência entre as categorias de Áreas Protegidas existentes no Pampa Argentina, Brasil e Uruguai e as categorias propostas pela IUCN

\begin{tabular}{|c|c|c|c|c|}
\hline \multirow{2}{*}{\multicolumn{2}{|c|}{$\begin{array}{l}\text { Categoria } \\
\text { IUCN }\end{array}$}} & \multicolumn{3}{|c|}{ Equivalência } \\
\hline & & Argentina & Brasil & Uruguai \\
\hline \multirow{4}{*}{ 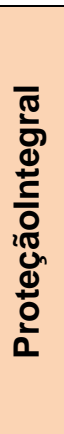 } & $\begin{array}{c}\text { Reserva Natural } \\
\text { Estrita }\end{array}$ & $\begin{array}{c}\text { Reserva Natural } \\
\text { Estrita }\end{array}$ & Estação Ecológica & - \\
\hline & Área Natural Silvestre & $\begin{array}{l}\text { Área Natural } \\
\text { Silvestre }\end{array}$ & $\begin{array}{l}\text { Reserva Biológica } \\
\frac{\text { Refúgio de Vida }}{\text { Silvestre }}\end{array}$ & - \\
\hline & Parque Nacional & $\begin{array}{l}\text { Parque Nacional e } \\
\text { Parque Provincial }\end{array}$ & $\frac{\text { Parque Nacional }}{\text { Parque Estadual }}$ & Parque Nacional \\
\hline & Monumento Natural & Monumento Natural & - & $\frac{\text { Monumento }}{\text { Natural }}$ \\
\hline \multirow{3}{*}{ 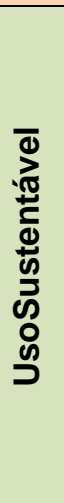 } & $\begin{array}{l}\text { Áreas de manejo de } \\
\text { habitat/espécies }\end{array}$ & $\begin{array}{c}\text { Áreas de Manejo de } \\
\text { Habitats e/ou } \\
\text { Espécies } \\
\text { Reserva Natural } \\
\text { Privada de Uso } \\
\text { Múltiplo } \\
\end{array}$ & $\frac{\frac{\text { Reserva Particular }}{\text { do Patrimônio }}}{\underline{\text { Natural }}}$ & $\begin{array}{c}\text { Áreas de Manejo } \\
\text { de Habitat e/ou } \\
\text { Espécies }\end{array}$ \\
\hline & $\begin{array}{l}\text { Paisagem terrestre e } \\
\text { marinha protegidas }\end{array}$ & Paisagem Protegida & 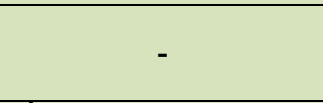 & $\begin{array}{l}\text { Paisagem } \\
\text { Protegida }\end{array}$ \\
\hline & $\begin{array}{l}\text { Área Protegida com } \\
\text { recursos manejados }\end{array}$ & $\begin{array}{l}\text { Reserva Natural com } \\
\text { Recursos Manejados }\end{array}$ & $\frac{\frac{\text { Área de Relevante }}{\text { Interesse Ecológico }}}{\frac{\text { Área de Proteção }}{\text { Ambiental }}}$ & $\begin{array}{l}\text { Área Protegida } \\
\text { com Recursos } \\
\text { Manejados }\end{array}$ \\
\hline
\end{tabular}

Fonte: Dudley (2008), Argentina (1980), Brasil (2000), Uruguai (2000).

Através do levantamento e espacialização das Áreas Protegidas instituídas no Pampa, observadas na figura 2, foi possível perceber uma distribuição heterogênea. De certo modo, observa-se uma concentração das áreas próximas a recursos hídricos importantes, como o Rio Uruguai, Lagoa dos Patos e Lagoa Mirim, e na própria região litorânea.

Inegavelmente, em um primeiro olhar, chama-se à atenção a província de Buenos Aires, na Argentina. É um "vazio de conservação" que reflete a realidade de exploração da terra. Conforme pode ser observada em estudos como Ernesto e Verón (2017) e Reboratti (2010), a província de Buenos Aires é uma das principais produtoras de grãos para exportação do país. E, ainda como destaca Pereira (2018), em grande parte, as propriedades destinadas para fins agrícolas estão em posse de empresas estrangeiras, demonstrando uma realidade que avança pela América Latina.

Essa realidade de uso da terra para fins produtivos voltados à exportação, sobretudo a soja, se reflete na província de Santa Fé e, em menores proporções, nas províncias de Entre Ríos, Corrientes e La Pampa, que ainda possuem relativa característica de criação de gado e ovelhas de forma extensiva. Ernesto e Verón (2017) citam que o Pampa argentino foi reduzido a menos de $10 \%$ de sua área original, estando principalmente representado pelas Áreas Protegidas do país. 
Figura 2 - Áreas Protegidas do Pampa Argentina, Brasil e Uruguai relacionadas de acordo com as categorias da IUCN

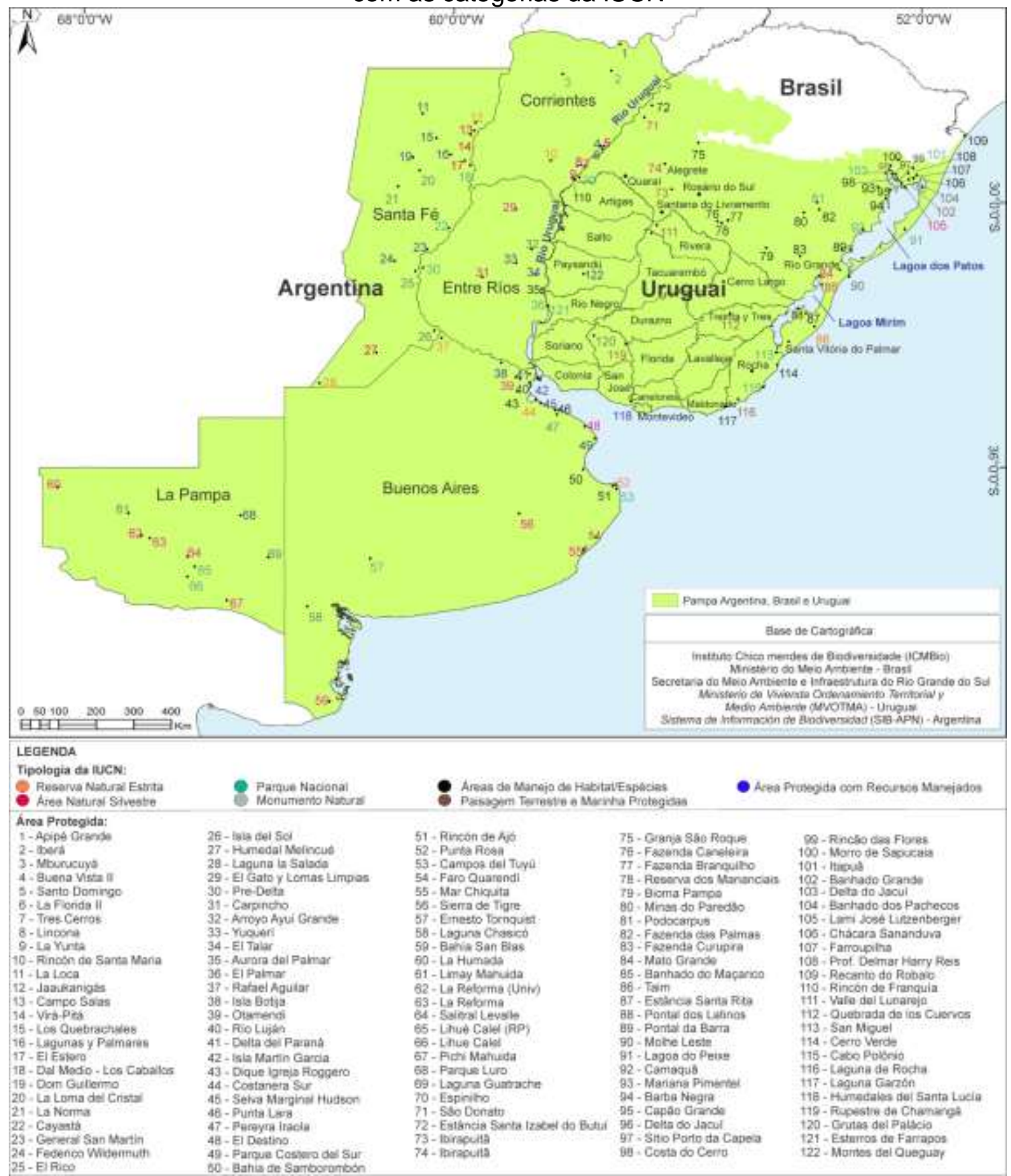

Fonte: elaborado pelos autores com base em: Argentina (2020), Brasil (2020), Porto Alegre (2020) e Uruguai (2020).

Esse perfil exploratório da terra se repete no Uruguai, onde há o predomínio do cultivo da soja para exportação, além da silvicultura, sobretudo o eucalipto, que ocupam extensas áreas que anteriormente eram de campos, promovendo uma conversão na paisagem tradicional do Pampa. As Áreas Protegidas no país ficam restritas, em sua maioria, ao litoral e às margens do Rio Uruguai. 
Como demonstram Achkar, Domínguez e Pesce (2015) a área plantada de soja passou de aproximadamente 12.000 hectares no ano 2000 para mais de um milhão de hectares em 2013. Nesse mesmo período, a produção cresceu em torno de 100 vezes, passando de 28.000 toneladas em 2000 para 2.800.000 toneladas em 2013.

No Pampa gaúcho a realidade é muito semelhante, sendo que a área plantada de soja aumentou 62\% no período de 2010/2011 a 2014/2015 (CHOMENKO, 2016). E a conservação acaba ficando restrita a áreas de proteção - as unidades de conservação, que no caso gaúcho são distribuídas de forma mais uniforme pelo território.

As Áreas Protegidas, ainda que de caráter de uso sustentável, acabam por se tornar ilhas de proteção em um Pampa que perde gradativamente sua principal característica cultural e econômica, baseada na atividade pastoril de forma extensiva, para se tornar uma fronteira agrícola em ampla expansão.

Dentre as categorias de manejo de Áreas Protegidas propostas pela IUCN, as que mais se destacam em números, no Pampa, são as destinadas à proteção integral, sendo 64 ao total, com predomínio da categoria Área Natural Silvestre - 27 áreas, encontradas, principalmente, na Argentina.

Já as Áreas Protegidas destinadas ao uso sustentável somam 58, destacando-se as 31 Áreas de Manejo de Habitat e/ou Espécies. Essas áreas concentram-se, principalmente, no Pampa brasileiro, conciliando, conforme seus objetivos de instituição, a conservação dos ecossistemas e o uso socioeconômico e cultural (BRASIL, 2000), característica típica do Pampa.

Ainda, no Pampa brasileiro, a maioria das Áreas Protegidas configura-se como de uso sustentável (26 áreas), sendo as Áreas de Manejo de habitat/espécies as mais representativas. No caso brasileiro, essa categoria da IUCN está amplamente representada pelas Reservas Particulares do Patrimônio Natural (RPPNs), totalizando 21 áreas. Destacase, também, a Área de Proteção Ambiental (APA) do lbirapuitã, com uma vasta extensão territorial (319.790 hectares), abarcando quatro municípios da fronteira oeste do Rio Grande do Sul - Alegrete, Quaraí, Santana do Livramento e Rosário do Sul, predominando as atividades da pecuária extensiva, agricultura familiar e turismo de base local.

Já as áreas de proteção integral estão em menor quantidade no Pampa brasileiro (14 áreas); onde se destaca a Reserva Ecológica do Taim - com 32.000 hectares (BRASIL, 2020), a qual se configura por uma vasta diversidade paisagística, com praias e cordões de dunas, lagunas, lagoas, banhados e campos, localizada nos municípios de Rio Grande e Santa Vitória do Palmar, no Rio Grande do Sul. 
No Uruguai, as Áreas Protegidas totalizam 13 ao total, sendo que de proteção integral estão em menor quantidade (quatro áreas), totalizando 44.175,00 hectares, um número pouco expressivo, conforme pode ser observado no quadro 5.

Já as Áreas Protegidas de uso sustentável do Pampa uruguaio, assim como do Pampa brasileiro, estão em maior representatividade, somam-se nove áreas. A Área Protegida com Recusos Manejados Humedalesdel Santa Lucía (86.517 hectares) segundo Uruguai (2020), localizada nos departamentos de Canelones, San José e Montevideo, protege a conexão entre o Rio Santa Lucia e o Rio da Prata e é a maior área em extensão localizada na zona costeira do Uruguai. Vale destacar a Paisagem Protegida Valle delLunarejo (29.286,00 hectares),área incluída na Reserva da Biosfera Quebradas del Norte (110.882,00 hectares), que está localizada no noroeste do departamento de Rivera, próximo de Artigas, Salto e o limite territorial do Brasil (SILVA, 2019).

Diferentemente do Brasil e do Uruguai, a Argentina possui 69 Áreas Protegidas no Pampa, destas 46 são de proteção integral, totalizando 204.060,70 hectares, ou seja, áreas dedicadas à proteção integral de flora, fauna e possíveis realizações de pesquisas científicas, apenas. A Reserva Natural Apipé Grande (27.500,00 hectares), localizada na Província de Corrientes é a área mais expressiva em tamanho.

Com relação às Áreas Protegidas de Uso Sustentável no Pampa argentino (23 áreas), somam-se 147.026,20 hectares, com destaque para a categoria Reserva Natural Privada de Uso Múltiplo (10 áreas), as quais, inclusive, se assemelham muito com as Reservas Particulares do Patrimônio Natural do Brasil. Nesta categoria destaca-se a Reserva Natural Privada de Uso Múltiplo Delta del Paraná, localizada na província de Buenos Aires, com 88.624,00 hectares.

A realidade das Áreas Protegidas vai ao encontro do cenário de conversão e degradação do Pampa, uma vez que possuem pequena representatividade, cerca de $1.175,014$ milhão de hectares, o que representa apenas $1,5 \%$ da área total do Pampa. Desse modo, o ecossistema passa a ser caracterizado, cada vez mais, como uma "fronteira agrícola", com a produção de commodities que não eram vistas por esses campos.

Desse modo, valorizar e conservar a biodiversidade do Pampa passa, necessariamente, pela discussão das Áreas Protegidas, tanto pela manutenção das existentes, quanto pelas propostas de novas áreas, sobretudo por ser o Pampa, dentre os biomas brasileiros, o que menos possui representatividade em quantidade e extensão de Áreas Protegidas.

Com relação ao território uruguaio, é importante destacar, como aponta Medina (2017), que existem nove áreas em estudo para ingressar legalmente no sistema do país, sendo uma da tipologia Parque Nacional, duas da tipologia Áreas Protegidas com Recursos 
Manejados e uma Área de Manejo de Habitat/Espécies; as demais ainda não possuem categoria definida. Até o final de 2020 essas áreas ainda não haviam sido instituídas.

Quadro 5 - Quantificação das Áreas Protegidas do Pampa Brasil, Argentina e Uruguai em extensão territorial

\begin{tabular}{|c|c|c|c|c|}
\hline \multirow{9}{*}{ 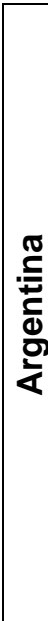 } & & Categoria & $\begin{array}{c}\text { Número de Áreas } \\
\text { Protegidas }\end{array}$ & $\begin{array}{c}\text { Áreas Protegidas } \\
\text { em hectares }\end{array}$ \\
\hline & \multirow{4}{*}{ 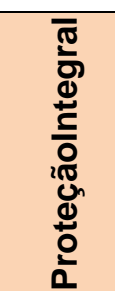 } & Reserva Natural Estrita & 6 & 5.517 \\
\hline & & Área Natural Silvestre & 20 & 51.172 \\
\hline & & Parque Nacional & 10 & 78.912 \\
\hline & & Monumento Natural & 10 & $68.459,7$ \\
\hline & \multirow{3}{*}{ ᄋ } & Áreas de manejo de habitat/ espécies & 5 & $5.127,2$ \\
\hline & & Paisagem terrestre e marinha protegidas & 1 & 5.575 \\
\hline & & Área Protegida com recursos manejados & 17 & 136.109 \\
\hline & \multirow{6}{*}{ 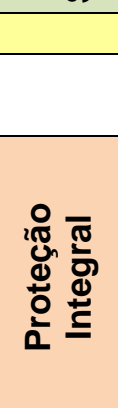 } & Total de Áreas Protegidas & 69 & $350.871,9$ \\
\hline \multirow{9}{*}{$\begin{array}{l}\overline{\bar{g}} \\
\overline{\mathbf{m}} \\
\overline{\mathbf{m}}\end{array}$} & & Categoria & $\begin{array}{l}\text { Número de Áreas } \\
\text { Protegidas }\end{array}$ & $\begin{array}{c}\text { Áreas Protegidas } \\
\text { em hectares }\end{array}$ \\
\hline & & Reserva Natural Estrita & 1 & 32.000 \\
\hline & & Área Natural Silvestre & 7 & 4.181 \\
\hline & & Parque Nacional & 6 & $66.125,545$ \\
\hline & & Monumento Natural & - & - \\
\hline & \multirow{3}{*}{ 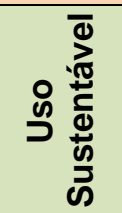 } & Áreas de manejo de habitat/ espécies & 23 & $5.543,714$ \\
\hline & & Paisagem terrestre e marinha protegidas & - & - \\
\hline & & Área Protegida com recursos manejados & 3 & $339.753,745$ \\
\hline & \multirow{6}{*}{ 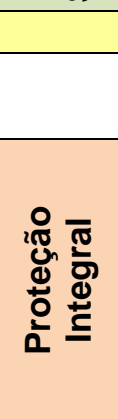 } & Total de Áreas Protegidas & 40 & 447.604 \\
\hline \multirow{9}{*}{$\begin{array}{l}\text { 종 } \\
\text { 올 } \\
\text { 논 }\end{array}$} & & Categoria & $\begin{array}{l}\text { Número de Áreas } \\
\text { Protegidas }\end{array}$ & $\begin{array}{c}\text { Áreas Protegidas } \\
\text { em hectares }\end{array}$ \\
\hline & & Reserva Natural Estrita & - & - \\
\hline & & Área Natural Silvestre & - & - \\
\hline & & Parque Nacional & 3 & 44.130 \\
\hline & & Monumento Natural & 1 & 45 \\
\hline & \multirow{3}{*}{ 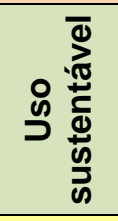 } & Áreas de manejo de habitat/ espécies & 3 & 47.125 \\
\hline & & Paisagem terrestre e marinha protegidas & 4 & 67.871 \\
\hline & & Área Protegida com recursos manejados & 2 & 217.368 \\
\hline & & Total de Áreas Protegidas & 13 & 376.539 \\
\hline
\end{tabular}

Fonte: Argentina (2020), Brasil (2020), Porto Alegre (2020), Uruguai (2020).

Além disso, o cenário de baixa representatividade poderia servir de impulsor para a consolidação de novas propostas de Áreas Protegidas para o Pampa brasileiro, como é o 
caso da proposição da Unidade de Conservação do Cerro do Jarau, no município de Quaraí, fronteira oeste do Rio Grande do Sul e a Proposta de Reserva da Biosfera do Pampa do Rio Grande do Sul (SILVA, 2019) na fronteira com o Uruguai.

No que tange à Argentina, foi reorganizado o web site oficial do Sistema de Informação de Biodiversidade e Administração de Parques Nacionais (ARGENTINA, 2020) o qual contém informações das Áreas Protegidas de todo território da Argentina, inclusive na esfera provincial. No país, as Áreas Protegidas que mais se destacam em quantidade são as identificadas em nível provincial: os Parques, os quais possuem características iguais aos Parques Nacionais, todavia instituído em esfera menor.

Nos países em estudo, pode-se afirmar que as províncias, os estados e os departamentos possuem autonomia para instituir suas áreas a serem protegidas e nomeálas conforme as categorias existentes em leis pré-definidas, que devem ser iguais ou mais restritivas que as leis de esfera nacional.

Nessa perspectiva, o Brasil, signatário da Convenção sobre a Diversidade Biológica (CDB), se comprometeu, conforme exposto em Weigand, Silva e Silva (2011), através da meta 11 de Aichi, que até 2020 fossem conservadas, por meio de Unidades de Conservação, $17 \%$ de cada um dos biomas do seu território, acordados durante a $10^{\text {a }}$ Conferência das Partes, realizada em Nagoya, em 2010.

Do mesmo modo, destacam-se o Uruguai e Argentina, países que também se comprometeram com o Protocolo de Nagoya, onde estão inseridas as Metas de Aichi. Até o momento, essas áreas ainda não foram instituídas, podendo representar uma importante estratégia de conservação da biodiversidade para alcançar as metas do Protocolo de Nagoya.

As Áreas Protegidas contribuem para a conservação do patrimônio natural e cultural, além de atuarem como importantes instrumentos de ordenamento territorial, controlando a inserção da soja e o cultivo de espécies exóticas para a produção de celulose, reduzindo o impacto do uso do solo, permitindo a manutenção dos serviços ambientais e promovendo a possibilidade de um desenvolvimento de base local e sustentável, valorizando a cultura, os saberes e o potencial turístico do território.

Para concluir, a identificação e espacialização das Áreas Protegidas no Pampa dos três países, balizadas a partir das categorias de manejo definidas pela IUCN, possibilitam notar que o Pampa está seriamente ameaçado e desprotegido, independentemente do país que o abrigue, preço que paga por ter sido um dos ambientes mais favorável ao estabelecimento humano e também um dos territórios periféricos mais produtivos.

Como a relação de coexistência entre o ser humano e o meio natural é antiga nesse ambiente, pensar iniciativas menos impactantes, que mantenham a relação mais harmônica possível com a biodiversidade do Pampa é um dos grandes pilares que sustentariam a 
conservação associada à manutenção da base cultural do Pampa. E, nessa perspectiva, as Áreas Protegidas, sobretudo as de uso sustentável, tornam-se importantes estratégias para essa manutenção.

Como expressa Bencke, Chomenko e Sant'Anna (2016), o manejo do gado de forma extensiva atua como um agente na contenção do avanço da vegetação lenhosa sobre as áreas campestres e é o grande responsável pela estabilidade ecológica dos campos. Ainda segundo o autor, tem sido verificado que a vegetação de áreas campestres, onde não há a ação do gado, perde diversidade ao longo do tempo, principalmente porque certas gramíneas que formam touceiras altas se tornam dominantes nessas condições e não deixam espaço para plantas menores e menos vigorosas, que tendem a desaparecer.

\section{CONSIDERAÇÕES FINAIS}

Ao final desta pesquisa, pode-se notar que apesar da noção de natureza preservada estar associada, comumente, à imagem de ambientes fortemente arborizados, ao sul das paisagens tropicais da América do Sul existe um vasto espaço onde as árvores se limitam a formar uma moldura ao longo dos cursos d'água e áreas de relevo mais acidentado. Essas paisagens, moldadas pela sociedade ao longo do tempo com a lida do gado, abrigam uma riqueza histórica, cultural e, sobretudo, guardam as marcas de uma natureza que se fez paisagem através da ação humana.

Todavia, essa riqueza do Pampa está seriamente ameaçada pelos impactos socioambientais causados pela inserção de monoculturas como a soja e o eucalipto que deixam um passivo ambiental, uma degradação social e cultural expressiva, tendo em vista que as consequências dessa conversão estão ligadas à concentração fundiária, a conflitos socioambientais, à perda de soberania alimentar, à vulnerabilidade econômica desses territórios, à fragilidade política e, por fim, a uma erosão cultural profunda de perdas de saberes, de perda de história, porque o capital não tem memória, tem acumulação momentânea.

A espacialização com a quantificação das Áreas Protegidas no Pampa demonstra uma disputa e apropriação do território por parte do capital. E, como apresentado aqui, o Pampa está desprotegido, existe uma pequena representatividade de Áreas Protegidas, independentemente do país que o abrigue, em extensões territoriais relativamente pequenas. Demonstrar à situação atual, correlacionando as realidades, sobretudo por ser o Pampa um ecossistema que extrapola fronteiras, torna-se uma medida inadiável. 


\section{REFERÊNCIAS}

ACHKAR, Marcel Borras; DOMÍNGUEZ, Ana; PESCE, Fernando. Hacia un escenario de gestión sustentable del territorio por cuencas hidrográficas en el contexto post-neoliberal en el Uruguay. Revista Científica Monfrague, Lisboa, v. 4, n. 1, p. 104-123, 2015.

ARGENTINA. Ley 10.479 de 25 de abril de 2017. Instituye el Sistema de Áreas Naturales Protegidas en el Territorio de la Provincia Entre Ríos. Entre Ríos, 2017. Disponível em: https://www.entrerios.gov.ar/ambiente/userfiles/files/archivos/Ley\%2010479\%20del\%202017 \%20(1)(1).pdf. Acesso em: 16 ago. 2020.

ARGENTINA. Ley 1.321 de 25 de julho de 1991. Instituye el Sistema Provincial de Areas Protegidas. La Pampa, 1991. Disponível em: https://argentinambiental.com/legislacion/lapampa/ley-1321-sistema-provincial-areas-protegidas/. Acesso em: 23 set. 2020.

ARGENTINA. Ley $n^{\circ} 22.351$, de 4 de noviembre de 1980. Parques nacionales. Buenos Aires, 1980. Disponível em: http://servicios.infoleg.gob.ar/infoleg Internet/anexos/1500019999/16299/texact.htm. Acesso em: 12 out. 2020.

ARGENTINA. Sistema de Información de Biodiversidad de la Administración de Parques Nacionales. Sistema de Información de Biodiversidad. Buenos Aires, 2020. Disponível em: https://sib.gob.ar/portada. Acesso em: 20 jun. 2020.

BENCKE, Glayson Ariel. Biodiversidade. In: CHOMENKO, Luiza; BENCKE, Glayson Ariel (org.). Nosso pampa desconhecido. Porto Alegre: Fundação Zoobotânica do Rio Grande do Sul, 2016. p. 60-75.

BENCKE, Glayson Ariel; CHOMENKO, Luiza; SANT'ANNA, Danilo Menezes. O que é o Pampa? In: CHOMENKO, Luiza; BENCKE, Glayson Ariel (org.). Nosso pampa

desconhecido. Porto Alegre: Fundação Zoobotânica do Rio Grande do Sul, 2016. p. 16-27.

BISHOP, Kevin et al. Speaking a common language: the uses and performance of the IUCN System of Management Categories for Protected Areas. Cardiff: Cardiff University; IUCN; UNEP-WCMC, 2004.

BRASIL. Decreto $n^{\circ} 5.758$ de 13 de abril de 2006. Institui o plano estratégico nacional de áreas protegidas - PNAP, seus princípios, diretrizes, objetivos e estratégias, e da outras providências. Diário Oficial da União: seção 1, Brasília, DF, p. 1, 17 abr. 2006. Disponível em: http://www.planalto.gov.br/ccivil_03/_ato2004-2006/2006/decreto/d5758.htm. Acesso em: 30 set. 2020.

BRASIL. Lei $n^{\circ} 9.985$, de 18 de julho de 2000. Regulamenta o art. 225, § 1ํㅡㄹ incisos I, II, III e VII da Constituição Federal, institui o Sistema Nacional de Unidades de Conservação da Natureza e dá outras providências. Diário Oficial da União: seção 1, Brasília, DF, p. 1, 19 jul. 2000. Disponível em: http://www.planalto.gov.br/ccivil_03/leis//9985.htm. Acesso em: 14 jun. 2020.

BRASIL. Lei $n^{\circ} 12.651$ de 25 de maio de 2012. Dispõe sobre a proteção da vegetação nativa; altera as Leis no-s 6.938, de 31 de agosto de 1981, 9.393, de 19 de dezembro de 1996, e 11.428, de 22 de dezembro de 2006; revoga as Leis nos 4.771, de 15 de setembro de 1965, e 7.754, de 14 de abril de 1989, e a Medida Provisória no 2.166-67, de 24 de agosto de 2001; e dá outras providências. Diário Oficial da União: seção 1, Brasília, DF, p. 1, 28 maio 2012. Disponível em:

http://www.planalto.gov.br/ccivil_03/_ato20112014/2012/lei//12651.htm\#: :text=Esta\%20Lei $\% 20$ estabelece\%20normas\%20gerais,n\%C2\%BA\%20571\%2C\%20de\%202012). Acesso em: 23 ago. 2020.

BRASIL. Ministério do Meio Ambiente. Dados georreferenciados. Brasília, DF: MMA, 2020. Disponível em: https://antigo.mma.gov.br/areas-protegidas/cadastro-nacional-de-ucs/dadosgeorreferenciados.html. Acesso em: 19 jun. 2020. 
Áreas Protegidas do Pampa - Argentina, Brasil e Uruguai: análise da distribuição espacial e...

BUENOS AIRES. Ley 10.907, de 26 de abril de 1990. Instituye el Sistema Provincial de Áreas Protegidas. Buenos Aires, 1990. Disponível em:

http://www.ecofield.net/Legales/BsAs/ley10907_BA.htm. Acesso em: 08 set. 2020.

CHOMENKO, Luiza. Transformações estruturais no pampa. In: I CONGRESSO

INTERNACIONAL DO PAMPA, 1., Santa Maria. Anais [...]. Santa Maria: UFSM, p. 1 - 14. 2016.

DIEGUES, Antônio Carlos Sant'Ana. O mito moderno da natureza intocada. São Paulo: Hucitec, 2002.

DUDLEY, Nigel (ed.). Guidelines for applying protected area management categories. Switzerland: IUCN, 2008. Disponível em:

https://www.iucn.org/sites/dev/files/import/downloads/iucn_assignment_1.pdf. Acesso em: 11 jul. 2020.

ERNESTO, Iscaro Mariano; VERÓN, Jimena. Políticas públicas para el sector agropecuario Argentino y SUS consecuencias sobre la conservación de la pampa. In: WIZNIEWSKY, Carmen Rejane Flores; FOLETO, Eliane Maria. Olhares sobre o pampa: um território em disputa. Porto Alegre: Evangraf, 2017. p. 24-45.

FIGUEIRÓ, Adriano Severo; SELL, Jaciele Carine. Paisagem e geoconservação nos territórios do pampa Brasil-Uruguai - reflexões para uma política transfronteiriça. Revista Ciência e Natura, Santa Maria, v. 42, 2020. Disponível em:

https://periodicos.ufsm.br/cienciaenatura/article/view/55109/html. Acesso em: 16 ago. 2020.

MEDEIROS, Rodrigo; GARAY, Irene. Singularidades do sistema de áreas protegidas para conservação e uso da biodiversidade brasileira. In: GARAY, Irene; BECKER,

Bertha Koiffmann. Dimensões humanas da biodiversidade: desafios de novas relações entre sociedade e natureza no século XXI. Petrópolis: Vozes, 2006. p. 159-184.

MEDEIROS, Rodrigo; IRVING, Marta de Azevedo; GARAY, Irene. A proteção da natureza no Brasil: evolução e conflitos de um modelo em construção. Revista de Desenvolvimento Econômico, Salvador, v. 6, n. 9, p. 83-93, jan. 2004.

MEDINA, Santiago. Políticas de la dirección nacional de medio ambiente de Uruguay en la conservación de los pastizales naturales. In: WIZNIEWSKY, Carmen Rejane Flores;

FOLETO, Eliane Maria. Olhares sobre o pampa: um território em disputa. Porto Alegre: Evangraf, 2017. p. 46-61.

PEREIRA, Lorena Izá. O processo de estrangeirização da terra na América Latina: o estudo de caso da Argentina. Boletim DATALUTA, Presidente Prudente, n. 125, p. 1-30, 2018.

Disponível em: http://www2.fct.unesp.br/nera/artigodomes/5artigodomes_2018.pdf. Acesso em: 27 jun. 2020.

PORTO ALEGRE. Secretaria do Meio Ambiente e Infraestrutura. Limite das unidades de conservação. Porto Alegre: Secretaria do Meio Ambiente e Infraestrutura, 2020. Disponível em: https://sema.rs.gov.br/limites-das-unidades-de-conservacao. Acesso em: 19 jun. 2020.

POSSAMAI, Paulo. A vida quotidiana na Colônia do Sacramento (1715-1735). São Paulo: Livros do Brasil, 2006.

REBORATTI, Carlos. Un mar de soja: la nueva agricultura en Argentina y sus consecuencias. Revista de Geografía Norte Grande, Santiago, n. 45, p. 63-73, 2010.

RICHARDSON, Roberto Jarry. Pesquisa social: métodos e técnicas. São Paulo: Atlas, 1999.

RIO GRANDE DO SUL. Decreto $n^{\circ} 53.037$ de 20 de maio de 2016. Institui e regulamenta o Sistema Estadual de Unidades de Conservação - SEUC. Porto Alegre, 2016. Disponível em: http://www.legislacao.sefaz.rs.gov.br/Site/Document.aspx?inpKey=251776\&inpCodDispositiv $\mathrm{e}=\&$ inpDsKeywords=53037. Acesso em: 10 set. 2020. 
SCHERL, Lea et al. As áreas protegidas podem contribuir para a redução da pobreza? Oportunidades e limitações. Gland: IUCN, 2006. Disponível em:

http://d2ouvy59p0dg6k.cloudfront.net/downloads/ppareportportuguese.pdf. Acesso em: 10 set. 2020.

SILVA, Franciele da. Áreas protegidas sob o viés da conservação transfronteiriça: proposição para o pampa do Rio Grande do Sul e Uruguai. 2019. Tese. (Doutorado em Geografia) - Universidade Federal de Santa Maria, Santa Maria, 2019.

SUERTEGARAY, Dirce Maria Antunes; SILVA, Luís Alberto Pires. Tchê pampa: histórias da natureza gaúcha. In: PILLAR, Valério de Patta et al. Campos sulinos: conservação e uso sustentável da biodiversidade. Brasília: MMA, 2009. p. 52-59.

TORNQUIST, Carlos Gustavo; BAYER, Cimélio. Serviços ambientais: oportunidades para a conservação dos Campos Sulinos. In: PILLAR, Valério de Patta et al. Campos sulinos:

conservação e uso sustentável da biodiversidade. Brasília: MMA, 2009. p. 122-127.

URUGUAI. Ley $n^{\circ} 17.234$ de 09 de março de 2000. Declaración de interes general. Sistema Nacional de Areas Naturales Protegidas. Montevidéu, 2000. Disponível em:

https://www.impo.com.uy/bases/leyes/17234-2000. Acesso em: 03 set. 2020.

URUGUAI. Ministerio de Vivienda y Ordenamiento Territorial. Sistema de información territorial. Montevidéu, 2020. Disponível em: https://sit.mvotma.gub.uy/sit/\#/inicio. Acesso em: 27 jun. 2020.

WEIGAND, Ronaldo; SILVA, Danielle Calandino; SILVA, Daniela de Oliveira. Metas de Aichi: situação atual no Brasil. Brasília, DF: UICN, 2011.

\section{AGRADECIMENTOS}

As autoras agradecem à Coordenação de Aperfeiçoamento de Pessoal de Nível Superior (CAPES) e ao Conselho Nacional de Desenvolvimento Científico e Tecnológico (CNPq) pelo financiamento da pesquisa.

Recebido: janeiro de 2021. Aceito: abril de 2021. 